Article

\title{
In Vitro Antioxidant, Antiinflammation, and Anticancer Activities and Anthraquinone Content from Rumex crispus Root Extract and Fractions
}

\author{
Taekil Eom ${ }^{1}$, Ekyune Kim ${ }^{2, *}$ and Ju-Sung Kim ${ }^{1, *(1)}$ \\ 1 Majors in Plant Resource and Environment, College of Agriculture \& Life Sciences, \\ SARI, Jeju National University, Jeju 63243, Korea; taekil7@hanmail.net \\ 2 College of Pharmacy, Catholic University of Daegu, Gyeongsan 38430, Korea \\ * Correspondence: ekyune@cu.ac.kr (E.K.); aha2011@jejunu.ac.kr (J.-S.K.); Tel.: +82-53-850-3619 (E.K.); \\ +82-64-754-3314 (J.-S.K.)
}

Received: 10 July 2020; Accepted: 7 August 2020; Published: 10 August 2020

\begin{abstract}
Rumex crispus is a perennial plant that grows in humid environments across Korea. Its roots are used in traditional Korean medicine to treat several diseases, including diseases of the spleen and skin and several inflammatory pathologies. In this study, different solvent fractions (n-hexane, dichloromethane, ethyl acetate, $n$-butanol, and aqueous fractions) from an ethanol extract of $R$. crispus roots were evaluated for the presence and composition of anthraquinone compounds and antioxidants by checking for such things as free radical scavenging activity, and electron and proton atom donating ability. In addition, anti-inflammatory activity was measured by NO scavenging activity and inflammatory cytokine production; furthermore, anti-cancer activity was measured by apoptosis-inducing ability. Polyphenolic and flavonoid compounds were shown to be abundant in the dichloromethane and ethyl acetate fractions, which also exhibited strong antioxidant activity, including free radical scavenging and positive results in FRAP, TEAC, and ORAC assays. HPLC analysis revealed that the dichloromethane fractions had higher anthraquinone contents than the other fractions; the major anthraquinone compounds included chrysophanol, emodin, and physcione. In addition, results of the anti-inflammatory assays showed that the ethyl acetate fraction showed appreciable reductions in the levels of nitric oxide and inflammatory cytokines (TNF- $\alpha$, IL-1 $\beta$, and IL-6) in Raw 264.7 cells. Furthermore, the anthraquinone-rich dichloromethane fraction displayed the highest anticancer activity when evaluated in a human hepatoma cancer cell line (HepG2), in which it induced increased apoptosis mediated by p53 and caspase activation.
\end{abstract}

Keywords: anthraquinone; free radical scavenging; inflammatory cytokines; apoptosis; Rumex crispus

\section{Introduction}

Reactive oxygen species (ROS), also known as oxygen-centered free radicals, are produced during normal metabolic processes and play an essential role in maintaining cellular homeostasis. ROS levels can increase as a result of exposure to chemical substances or other environmental stress resulting in oxidative stress [1]. When the intrinsic antioxidant system within an organism is damaged, it is not possible to remove these free radicals and the resulting oxidative stress can lead to various chronic diseases. A state of chronic oxidative stress can cause oxidative damage to various cellular components, including cell membranes, DNA, and proteins. It can also result in the activation of systemic chronic inflammatory responses via a number of different intracellular signaling pathways, ultimately exacerbating a variety of pathological conditions, including cardiovascular diseases, cancer, dementia, diabetes, autoimmune disorders, and aging [2]. One of the underlying signaling mechanisms 
triggered by excessive ROS generation is the activation of nuclear transcription factor $\mathrm{kB}(\mathrm{NF}-\mathrm{kB})$, which acts as a transcriptional regulator of the innate immune system and can stimulate the release of a variety of pro-inflammatory cytokines from various tissues [3,4].

Inflammation is one of the self-defense responses used by organisms to defend against a wide range of external stimuli; however, excessive or prolonged inflammation can lead to the development of serious pathologies. The inflammatory response is characterized by the activation of macrophages and subsequent increases in the secretions of nitric oxide (NO), pro-inflammatory cytokines such as interleukin-1 $\beta$ (IL-1 $\beta$ ), interleukin-6 (IL-6), and tumor necrosis factor- $\alpha$ (TNF- $\alpha$ ), and cell adhesion molecules [5]. ROS-mediated chronic inflammatory responses can be inhibited by antioxidants. Various antioxidant compounds have been described in the literature with varying degrees of efficacy. The versatility of these compounds makes them ideal candidates for novel therapies. Various natural products have been shown to exhibit antioxidant properties and hence this is a growing field of interest. Plants have been identified as an especially rich source of antioxidant compounds, with most containing phenolic groups, which are known to play a crucial role in the removal of ROS. These phenolic compounds are generally secondary metabolites involved in stress responses and are known to perform various physiological functions, including antioxidant, anti-inflammatory, and anticancer functions [6,7]. The Rumex genus belongs to the Polygonaceae family and includes R. crispus, R. acetosella, R. acetosa, R. aquatica, R. longifolius, R. gmelini, R. conglomeratus, and R. maritimus. R. crispus is a perennial plant endemic to Korea which is found growing in humid environments. Its roots have been used as traditional medicinal materials in the treatment of several pathological conditions, including bladder infections, gallbladder disease, skin disease, and lymph node disorders. They have also been used as an adjuvant therapy in oriental medicine strategies used to treat cancer [8,9]. Several bioactive components of $R$. crispus have been identified and include saponins, tannins, flavonoids, essential oils, and anthraquinone derivatives such as chrysophanol and emodin [10-12]. This study was designed to evaluate the potential of new bioactive substances from $R$. crispus identified by analyzing their antioxidant, anti-inflammatory, and anticancer activities using root extracts and various extract fractions.

\section{Materials and Methods}

\subsection{Materials}

2,2-Diphenyl-1-picrylhydrazyl (DPPH), 2,2'-azobis(2-methylpropionamidine) dihydrochloride (AAPH), 2,2'-azino-bis(3-ethylbenzothiazoline-6-sulfonic acid) diammonium salt (ABTS), 2', $7^{\prime}$ dichlorofluorescin (DCFH), trolox, Folin-Ciocalteu reagent, 2,4,6-tris (2-pyridyl)-s-triazine (TPTZ), gallic acid, quercetin, trichloroacetic acid (TCA), aluminum chloride hexahydrate $\left(\mathrm{AlCl}_{3} \cdot 6 \mathrm{H}_{2} \mathrm{O}\right)$, phenazine methosulphate (PMS), $\beta$-nicotinamide adenine dinucleotide reduced disodium salt (NADH), nitro blue tetrazolium tablet (NBT), thiazolyl blue tetrazolium bromide (MTT), dimethyl sulfoxide (DMSO), and lipopolysaccharide (LPS) were purchased from Sigma-Aldrich (St. Louis, MO, USA). The human hepatoma cancer cell line HepG2 and mouse macrophage cell line Raw 264.7 were obtained from the American Type Culture Collection (Manassas, VA, USA). All western blot antibodies were obtained from Santa Cruz Biotechnology (Logan, UT, USA). All other chemicals used in this study were at least $99 \%$ pure.

\subsection{Preparation of Extracts and Fractions}

Dried R. crispus root powder was extracted three times using ten times its weight of ethanol and subjected to reflux for $12 \mathrm{~h}$. After drying by evaporation in a vacuum rotary evaporator, the extract was suspended in water and fractionated with $n$-hexane (HF), dichloromethane (DCMF), ethyl acetate (EAF), $n$-butanol, (BF), and water (AF) three times, respectively. A total of five fractions were obtained after the solvents were removed. 


\subsection{Determination of Total Phenol and Flavonoid Contents}

The total phenolic content was quantified using Folin-Ciocalteu reagent and a Gallic acid standard [13]. Briefly, $100 \mu \mathrm{L}$ of each sample solution $(1 \mathrm{mg} / \mathrm{mL})$ was mixed in a test tube containing $3.5 \mathrm{~mL}$ distilled water and $500 \mu \mathrm{L} \mathrm{50 \%} \mathrm{Folin-Ciocalteu} \mathrm{reagent.} \mathrm{The} \mathrm{mixture} \mathrm{was} \mathrm{then} \mathrm{allowed} \mathrm{to} \mathrm{react}$ for $2 \mathrm{~h}$, after which $500 \mu \mathrm{L}$ of $20 \% \mathrm{Na}_{2} \mathrm{CO}_{3}$ was added. The mixture was then placed in a dark room for $1 \mathrm{~h}$, and the absorbance at $720 \mathrm{~nm}$ was recorded using a SpectraMax M2 ${ }^{\mathrm{e}}$ microplate reader (Molecular Device, Sunnyvale, CA, USA). The total phenolic contents are expressed as gallic acid equivalents (mM GAE/g).

To analyze total flavonoid content of each sample, $500 \mu \mathrm{L}$ of each sample $(1 \mathrm{mg} / \mathrm{mL})$ was mixed with $100 \mu \mathrm{L}$ of $10 \%(w / v)$ aluminum chloride and $100 \mu \mathrm{L}$ of $1.0 \mathrm{M}$ potassium acetate. Then, $1.5 \mathrm{~mL}$ of ethanol and $2.8 \mathrm{~mL}$ of distilled water were added and mixed in. The mixture was then placed in a dark room for $1 \mathrm{~h}$, and the absorbance at $415 \mathrm{~nm}$ was recorded using a SpectraMax M2 ${ }^{\mathrm{e}}$ microplate reader [14]. The total flavonoid content is expressed as quercetin equivalents (mM QE/g).

\subsection{HPLC Analysis of Anthraquinone Derivative}

Anthraquinone derivatives in the R. crispus extracts and solvent fractions were analyzed using high performance liquid chromatography coupled with a PDA detection system (Shimadzu Prominence, Japan). The analysis was performed on a Triat C-18 column $(250 \mathrm{~mm} \times 4.6 \mathrm{~mm}, 5 \mu \mathrm{m})$ from YMC Co., Ltd. The column temperature was set to $40{ }^{\circ} \mathrm{C}$ and the detection wavelength was set to $450 \mathrm{~nm}$. The mobile phase consisted of water containing $0.1 \%$ TFA (Trifluoro aceticacid) and $0.1 \%$ TFA containing methanol (B) with the gradient program set as follows: isocratic $20 \% \mathrm{~B}$ at $0-5 \mathrm{~min}$, linear gradient $20-80 \% \mathrm{~B}$ at 5-15 min, linear gradient $80-90 \%$ B at 15-30 min, linear gradient $90-100 \%$ B at 30-35 min, isocratic $100 \% \mathrm{~B}$ at $35-40 \mathrm{~min}$ with flow rate of $1.0 \mathrm{~mL} / \mathrm{min}$.

\subsection{DPPH Radical Scavenging Activity}

The DPPH radical scavenging effect was evaluated using the published method with slight modifications [15]. Briefly, $160 \mu \mathrm{L}$ of $1.5 \times 10^{-4} \mathrm{M}$ DPPH solution was mixed with $40 \mu \mathrm{L}$ of a sample solution, incubated at room temperature for $30 \mathrm{~min}$, and then absorbance at $540 \mathrm{~nm}$ was evaluated using a SpectraMax $\mathrm{M} 2{ }^{\mathrm{e}}$ microplate reader. The scavenging activity of the DPPH radicals was calculated as follows: ((Abs blank-Abs sample)/Abs blank $) \times 100$. The radical scavenging activity was expressed as a concentration that inhibited the radicals by $50 \%$.

\subsection{Hydroxyl Radical Scavenging Activity}

The hydroxyl radical scavenging activity was determined using the method described by Label and Bondy [16]. Briefly, the sample was mixed with $1 \mathrm{mM} \mathrm{H}_{2} \mathrm{O}_{2}$ and $0.2 \mathrm{mM} \mathrm{FeSO}_{4}$, and incubated at $37^{\circ} \mathrm{C}$ for $5 \mathrm{~min}$. Esterase-treated $2 \mu \mathrm{M}$ DCHF-DA was then added and the change in fluorescence was monitored on a SpectraMax $\mathrm{M}^{\mathrm{e}}$ microplate reader, with excitation and emission wavelengths of $460 \mathrm{~nm}$ and $530 \mathrm{~nm}$, respectively, for $30 \mathrm{~min}$. The scavenging activity of the hydroxyl radicals was calculated as follows: ((FLU blank-FLU sample)/FLU blank $) \times 100$. The radical scavenging activity was expressed as a concentration that inhibited the radicals by $50 \%$.

\subsection{Superoxide Radical Scavenging Activity}

The superoxide radical scavenging effect was evaluated using the method reported by Liu et al. [17] with minor modifications. Briefly, the reagent mixture containing a $50 \mu \mathrm{L}$ aliquot of a sample solution, $50 \mu \mathrm{L}$ of $150 \mu \mathrm{M}$ NBT, $50 \mu \mathrm{L}$ of $468 \mu \mathrm{M}$ NADH, and $50 \mu \mathrm{L}$ of $60 \mu \mathrm{M}$ phenazine methosulfate was incubated at room temperature for $5 \mathrm{~min}$. The absorbance was measured at $560 \mathrm{~nm}$ and compared to the blank, and the superoxide anion radical scavenging activity was then calculated using the following equation: Scavenging effect, $\%=(($ Abs sample - Abs blank $) /$ Abs blank $) \times 100$. The radical scavenging activity was expressed as a concentration that inhibited the radicals by $50 \%$. 


\subsection{TEAC Assay}

The TEAC method is based on the reaction of $\mathrm{ABTS}^{\bullet+}$ ions and was carried out according to the method described by Zulueta et al. [18] with minor modifications. An $\mathrm{ABTS}^{\bullet+}$ working solution was prepared daily by diluting the $\mathrm{ABTS}^{\bullet+}$ stock solution with distilled water to get an absorbance of $0.07 \pm 0.02$ at $734 \mathrm{~nm}$. Briefly, $50 \mu \mathrm{L}$ aliquots of the sample solutions were each mixed with $1.0 \mathrm{~mL}$ $\mathrm{ABTS}^{\circ+}$ working solution. Each mixture was incubated at $25^{\circ} \mathrm{C}$ in the dark for $5 \mathrm{~min}$ and absorbance was measured using a SpectraMax M2e microplate reader at $734 \mathrm{~nm}$. The sample extract activity was expressed as $\mathrm{mM}$ trolox/g dry sample and all determinations were carried out in triplicate.

\subsection{ORAC Assay}

ORAC measures the antioxidant inhibition of peroxyl-radical-induced oxidations and reflects radical chain-breaking antioxidant activity by $\mathrm{H}$-atom transfer. This assay is based on the scavenging of peroxyl radicals generated by AAPH, which prevents the degradation of the fluorescein probe, and consequently, prevents the loss of fluorescence. For this study, we used the method described by Zulueta et al. [18]. A $75 \mathrm{mM}$ phosphate buffer ( $\mathrm{pH}$ 7.4) was used for all sample dilutions and reagent preparations. Aliquots of the sample extractions $(50 \mu \mathrm{L})$ and the $150 \mu \mathrm{L} 75 \mathrm{nM}$ fluorescein solutions were placed in 96-black well microplates. The mixture was preincubated for $10 \mathrm{~min}$ at $37^{\circ} \mathrm{C}$. The reaction was initiated by adding $25 \mu \mathrm{L}$ of $120 \mathrm{mM}$ AAPH solution and the changes in the fluorescence were monitored using a SpectraMax $\mathrm{M}^{\mathrm{e}}$ microplate reader, with excitation and emission wavelengths of $460 \mathrm{~nm}$ and $530 \mathrm{~nm}$, respectively, for $60 \mathrm{~min}$. The sample extract activity was expressed as $\mathrm{mM}$ of trolox/g dry sample and all determinations were carried out in triplicate.

\subsection{FRAP Assay}

The FRAP value was determined using the method described by Benzie et al. [19] with slight modifications. Briefly, $50 \mu \mathrm{L}$ aliquots of the sample extracts each were mixed with $1.5 \mathrm{~mL}$ FRAP working reagent prepared fresh daily. The FRAP working reagent consisted of 10 volumes of $300 \mathrm{mM}$ acetate buffer ( $\mathrm{pH}$ 3.6) mixed with 10 volumes of $20 \mathrm{mM} \mathrm{FeCl}_{3}$. In addition, one volume of $10 \mathrm{mM}$ TPTZ in $40 \mathrm{mM} \mathrm{HCl}$, was also added to each sample and the final mixture was incubated at $37^{\circ} \mathrm{C}$ in the dark for $30 \mathrm{~min}$. Absorbance was measured after $30 \mathrm{~min}$ at $593 \mathrm{~nm}$. The activities of each extract are expressed as $\mathrm{mM}$ of $\mathrm{FeSO}_{4} / \mathrm{g}$ dry sample and all determinations were carried out in triplicate.

\subsection{Cell Culture and Cell Viability Assays}

HepG2 and Raw 264.7 cells were cultured in Dulbecco's modified Eagle's medium supplemented with $10 \%$ heated-inactivated fetal bovine serum, penicillin $(100 \mathrm{U} / \mathrm{mL})$, and streptomycin $(100 \mu \mathrm{g} / \mathrm{mL})$ at $37^{\circ} \mathrm{C}$ in a humidified atmosphere of $95 \%$ air and $5 \% \mathrm{CO}_{2}$. The medium was changed every other day. Cell viability was measured using the MTT assay, which is based on the conversion of MTT to formazan crystals by mitochondrial dehydrogenases. Cells were cultured in 96-well plates $\left(2.0 \times 10^{4}\right.$ cells/well $)$ with serum free media and treated with different concentrations of sample for $24 \mathrm{~h}$. The R. crispus extracts and its solvent fractions were dissolved in 10\% DMSO. The final concentration of DMSO in the culture medium never exceeded $0.1 \%$. For the assay, $100 \mu \mathrm{L}$ of MTT solution was added to each well and incubated for $4 \mathrm{~h}$. Finally, $200 \mu \mathrm{L}$ of DMSO was added to dissolve the formazan crystals and the absorbance was measured using a SpectraMax M2 ${ }^{\mathrm{e}}$ microplate reader at $540 \mathrm{~nm}$.

\subsection{NO Production}

Raw 264.7 cells were cultured in 96-well plates using media without phenol red and pre-treated for $1 \mathrm{~h}$ with each of the test substrates. Cellular NO production was induced by adding $1 \mu \mathrm{g} / \mathrm{mL}$ LPS and incubating the mixture for $24 \mathrm{~h}$. After incubation, $50 \mu \mathrm{L}$ of conditioned media containing nitrite (primary stable oxidation product of $\mathrm{NO}$ ) was mixed with the same volume of Griess reagent and 
incubated for $15 \mathrm{~min}$. Absorbance of the mixture was measured using a SpectraMax $\mathrm{M}^{\mathrm{e}}{ }^{\mathrm{e}}$ microplate reader at $550 \mathrm{~nm}$.

\subsection{Cytokine Analysis}

Production of IL-1 $\beta$, IL-6, and TNF- $\alpha$ in Raw 264.7 cells was evaluated using Quantikine ELISA kits (R\&D Systems, Minneapolis, MN, USA) as per the manufacturer's instructions. Cells were treated with different concentrations of test materials for $1 \mathrm{~h}$ and production of IL-1 $\beta$, IL-6, and TNF- $\alpha$ was stimulated by adding $1 \mu \mathrm{g} / \mathrm{mL}$ LPS and incubating for a further $24 \mathrm{~h}$. The supernatant was collected and the concentrations of IL- $1 \beta$, IL- 6 , and TNF- $\alpha$ were quantified using the relevant kit protocol.

\subsection{Annexin V-FITC/PI Analysis}

To determine the magnitude of the apoptosis induced by DCMF, an Annexin V-fluorescein isothiocyanate (FITC) apoptosis detection kit (BD Pharmingen, San Diego, CA, USA) was used. Briefly, the cells were harvested, washed with PBS and binding buffer, and then stained with FITC-conjugated Annexin V and propidium iodide (PI) for $30 \mathrm{~min}$ in the dark. The mixture was then analyzed using an LSR Fortessa flow cytometer (Becton Dickinson, San Jose, CA, USA) according to the manufacturer's protocol.

\subsection{Western Blot}

HepG2 cells were cultured in DMEM at a density of $1 \times 10^{4}$ cells in $10 \mathrm{~cm}^{2}$ cell culture dishes and incubated for $24 \mathrm{~h}$. The cells were treated with different concentrations of DCMF for $24 \mathrm{~h}$. The cells were lysed using RIPA buffer (Sigma-Aldrich, St. Louis, MO, USA) and supernatants were treated with a protease inhibitor cocktail and centrifuged at $2300 \times \mathrm{g}$ for $10 \mathrm{~min}$ to remove the insoluble fraction. The protein concentrations of the supernatants were determined using a BCA protein assay kit (Thermo Science, Rockford, IL, USA).

The same amounts of cell lysates were analyzed on 10\% SDS-PAGE and the proteins were blotted onto immuno-blot nitro-cellulose membranes and blocked with 5\% BSA in TBS containing $0.1 \%$ Tween 20 (TBS-T) for $1 \mathrm{~h}$. Then the primary monoclonal antibodies were added to the TBS-T (1:1000 dilutions) and incubated overnight. Antibody binding was detected using a horseradish peroxidase secondary antibody and enhanced using a chemi-luminescence ECL assay kit (Bio-Rad, Hercules, CA, USA) according to the manufacturer's instructions and imaged on a FUJIFILM LAS-4000 mini system (Tokyo, Japan). The basal levels of the proteins were normalized against $\beta$-actin or $\beta$-tubulin.

\subsection{Statistical Analysis}

Each experiment was performed at least three times and results are presented as means \pm SDs (standard deviations). Statistical comparisons of the mean values were performed using one-way ANOVA followed by Duncan's multiple range test using Minitab 17 software (Minitab Inc., IL, USA, State College, PA, USA). Differences were considered significant at $p<0.05$.

\section{Results and Discussion}

\subsection{Analysis of Polyphenol, Flavonoid, and Anthraquinone Contents}

Polyphenols are aromatic compounds containing more than two phenolic hydroxyl groups. They are classified into phenolic acids (e.g., caffeic acid and chlorogenic acid) and flavonoids (e.g., kaempferol and catechin) [20]. The total polyphenol and flavonoid contents for each of the extracts are described in Table 1. Analysis of the total polyphenol and flavonoid content in the R. crispus extracts and solvent fractions revealed that polyphenol content was highest in the ethyl acetate fraction (EAF), followed by the dichloromethane fraction (DCMF), ethanol extract (EE), aqueous fraction $(\mathrm{AF})$, butanol fraction (BF), and finally, the hexane fraction (HF). The highest flavonoid content was detected in the DCMF, followed by HF, EAF, EE, AF, and BF. The antioxidant activity of polyphenolic 
compounds is attributed to their activities as electron donors and free radical scavengers. Therefore, the antioxidant effects of various plant extracts have been shown to be strongly linked with the relative phenolic content [21,22].

Table 1. Total phenolic and flavonoid contents of Rumex crispus L. root extracts and fractions ${ }^{1}$.

\begin{tabular}{ccc}
\hline Samples $^{2}$ & Total Phenols $\left(\mathbf{m g}\right.$ GAE/g) $^{\mathrm{T}}$ & Total Flavonoids $(\mathrm{mg}$ QE/g) \\
\hline EE & $21.84 \pm 1.15^{\mathrm{c}}$ & $14.58 \pm 0.61^{\mathrm{d}}$ \\
HF & $10.68 \pm 0.06^{\mathrm{e}}$ & $24.15 \pm 0.47^{\mathrm{b}}$ \\
DCMF & $28.16 \pm 1.42^{\mathrm{b}}$ & $30.67 \pm 0.97^{\mathrm{a}}$ \\
EAF & $83.26 \pm 2.49^{\mathrm{a}}$ & $21.31 \pm 0.33^{\mathrm{c}}$ \\
BF & $19.03 \pm 1.04^{\mathrm{c}, \mathrm{d}}$ & $11.28 \pm 0.40^{\mathrm{e}}$ \\
AF & $19.79 \pm 0.32^{\mathrm{c}, \mathrm{d}}$ & $11.52 \pm 0.70^{\mathrm{e}}$ \\
\hline
\end{tabular}

1 Values are each expressed as a mean \pm SD $(n=3) .{ }^{2}$ EE: ethanol extracts. HF: $n$-hexane fractions. DCMF: dichloromethane fraction. EAF: ethyl acetate fraction. BF: $n$-buthanol fractions. AF: aqueous fraction. a-e Means with different superscripts in the same column are significantly different at $p<0.05$.

An HPLC-DAD method was applied to identify the five anthraquinones, including aloeemodin, chrysophanol, emodin, physcion, and rhein, in R. crispus extracts and solvent fractions. Figure S1 shows the typical chromatograms of the standard solution containing the five anthraquinones and the $R$. crispus extracts and solvent fractions. The retention times of the aloeemodin, rhein, emodin, chrysophanol, and physcion were 22.2, 23.7, 27.3, 29.9, and $33.2 \mathrm{~min}$, respectively (Figure S1). The concentrations of the major anthraquinones from $R$. crispus extracts and solvent fraction are summarized in Table 2. The major anthraquinones found in the samples analyzed in this study were chrysophanol, emodin, and physcion. The anthraquinone content was highest in the DCMF, followed by HF, EE, EAF, and BF. One gram of DCMF contained $66.96 \mathrm{mg}$ chrysophanol, $160.43 \mathrm{mg}$ emodin, and $34.90 \mathrm{mg}$ physcion. One gram of HF contained $48.64 \mathrm{mg}$ chrysophanol, $14.64 \mathrm{mg}$ emodin, and $15.43 \mathrm{mg}$ physcion. However, none of the anthraquinone compounds were detected in the AF. Anthraquinone derivatives are naturally occurring quinone compounds including naphthoquinones and benzoquinones, and are present in large quantities in plants such as Polygonaceae (Rheum, Rumex), Fabaceae (Cassia), Liliaceae (Aloe), Rhamnaceae (Rhamnus), and Rubiaceae (Asperula, Coelospermum, Coprosma, Galium, Morinda, and Rubia) [23]. Lim et al. [24] analyzed the anthraquinone contents of various Rumex species and found that emodin was highest in R. crispus. In addition, Smolarz et al. [25] investigated the anthraquinone contents of various Rumex species and found that the highest anthraquinone concentrations were found in the root extracts, with these extracts having substantially higher concentrations than those of the fruit extracts (70-fold) and the leaf extracts (10-fold). Most of these compounds are nonpolar with a 9,10-anthracenedione basic structure-a tricyclic aromatic organic compound with a formula of $\mathrm{C}_{14} \mathrm{H}_{8} \mathrm{O}_{2}$, which is extracted by polar solvents like ethanol/water mixtures, ethanol, methanol, and acetone [26]. It has also been reported that these compounds are well dispersed in nonpolar solvents, such as hexane and dichloromethane [27].

Table 2. Anthraquinone derivative contents of Rumex crispus L. root extracts and fractions ${ }^{1}$.

\begin{tabular}{|c|c|c|c|c|c|c|}
\hline \multirow{2}{*}{ Samples $^{2}$} & \multicolumn{6}{|c|}{ Concentration $(\mathrm{mg} / \mathrm{g})$} \\
\hline & Aloeemodin & Chrysophanol & Emodin & Physcion & Rhein & Total \\
\hline $\mathrm{EE}$ & $0.141 \pm 0.002^{c}$ & $9.714 \pm 0.02^{c}$ & $8.779 \pm 0.011^{\mathrm{d}}$ & $4.282 \pm 0.006^{c}$ & $0.057 \pm 0.002^{\mathrm{d}}$ & $22.97 \pm 0.026^{c}$ \\
\hline $\mathrm{HF}$ & $0.048 \pm 0.006^{\mathrm{e}}$ & $48.644 \pm 0.171^{b}$ & $14.64 \pm 0.037^{b}$ & $15.433 \pm 0.058^{b}$ & $0.106 \pm 0.001^{c}$ & $79.095 \pm 0.259^{b}$ \\
\hline DCMF & $0.595 \pm 0.003^{a}$ & $66.964 \pm 0.244^{\mathrm{a}}$ & $160.434 \pm 0.651^{\mathrm{a}}$ & $34.896 \pm 0.109^{a}$ & $0.466 \pm 0.002^{\mathrm{a}}$ & $263.356 \pm 0.666^{a}$ \\
\hline EAF & $0.218 \pm 0.001^{b}$ & $3.154 \pm 0.009^{d}$ & $13.627 \pm 0.053^{c}$ & $1.722 \pm 0.006^{\mathrm{d}}$ & $0.151 \pm 0.002^{b}$ & $18.923 \pm 0.062^{d}$ \\
\hline $\mathrm{BF}$ & $0.181 \pm 0.007^{\mathrm{d}}$ & $0.083 \pm 0.002^{\mathrm{e}}$ & $0.639 \pm 0.004^{\mathrm{e}}$ & $0.054 \pm 0.002^{\mathrm{e}}$ & $0.001>$ & $0.856 \pm 0.006^{\mathrm{e}}$ \\
\hline $\mathrm{AF}$ & - & - & - & - & - & - \\
\hline
\end{tabular}




\subsection{Radical Scavenging Activities of R. crispus Extracts and Fractions}

The DPPH radical scavenging assay is used to assess the electron-donating ability of antioxidants to quench free radicals. In $R$. crispus root extracts and fractions, we observed that DPPH radical scavenging was the highest in the EAF, followed by the EE, BF, DCMF, and HF (Table 3). While the antioxidant activities of $R$. crispus leaf and fruit extracts have been extensively studied, there is limited information on these activities in its root extracts. Yildirim et al. [28] have reported that DPPH radical scavenging activity is higher in R. crispus fruit extracts with high polyphenol content than in leaf extracts. Consistent with the findings of this study, the radical scavenging ability of $R$. japonica extracts and fractions has also been found to be highest in extracts with high polyphenol content and low in extracts with low polyphenol content [29].

We measured the scavenging capacities of these extracts for hydroxyl radicals using the Fenton reaction assay, which is based on fluorescence emission after hydroxyl radicals generated by $\mathrm{H}_{2} \mathrm{O}_{2}$ and $\mathrm{Fe}^{2+}$ via the Fenton reaction with DCFH. The scavenging ability increased in all the extracts and fractions in a concentration-dependent manner. This is similar to the results for Trolox, a well-known antioxidant. Anusuya et al. [30] have reported that the hydroxyl radical scavenging abilities of Rubus nepalensis extracts are closely related to their polyphenol contents. Moreover, phenolic hydroxyl groups are known to rapidly quench hydroxyl radicals by donating hydrogen atoms or electrons, as evidenced by measuring the hydroxyl radical scavenging abilities of various phenolic acids [31]. This study also demonstrated that the EAF and DCMF which both had high polyphenol and flavonoid contents also had the highest hydroxyl scavenging abilities (Table 3).

Superoxide radicals have very low reactivity; however, within the body, they are rapidly transformed into $\mathrm{H}_{2} \mathrm{O}_{2}$, and then via the Fenton reaction, to highly reactive hydroxyl radicals, which interact with biomolecules, causing tissue damage. As with hydroxyl radical scavenging, the superoxide radical scavenging ability of $R$. crispus root extracts was strongest in the EAF and DCMF, followed by EE, BF, AF, and HF (Table 3). In a study of the antioxidant properties of Rumex hastatus extracts and fractions, superoxide radical scavenging ability has been linked to flavonoid content rather than phenolic content [32]. The present study showed that the EAF and DCMF fractions, with high flavonoid content, exhibited the highest superoxide radical scavenging ability.

Table 3. Free radical scavenging activity of Rumex crispus L. root extracts and fractions ${ }^{1}$.

\begin{tabular}{cccc}
\hline \multirow{2}{*}{ Samples $^{2}$} & \multicolumn{3}{c}{ EC $^{\mathbf{5 0}}{ }^{3}$} \\
\cline { 2 - 4 } & DPPH Radical & Hydroxyl Radical & Superoxide Radical \\
\hline EE & $46.5 \pm 2.6^{\mathrm{b}}$ & $19.65 \pm 0.64^{\mathrm{c}}$ & $51.72 \pm 2.00^{\mathrm{c}}$ \\
HF & $126.2 \pm 1.3^{\mathrm{e}}$ & $62.47 \pm 2.44^{\mathrm{f}}$ & $>200^{\mathrm{f}}$ \\
DCMF & $65.6 \pm 1.2^{\mathrm{d}}$ & $0.54 \pm 0.13^{\mathrm{a}}$ & $45.83 \pm 2.00^{\mathrm{b}}$ \\
EAF & $11.9 \pm 2.5^{\mathrm{a}}$ & $0.65 \pm 0.06^{\mathrm{a}}$ & $4.45 \pm 0.42^{\mathrm{a}}$ \\
BF & $55.1 \pm 1.5^{\mathrm{c}}$ & $3.84 \pm 0.35^{\mathrm{d}}$ & $61.00 \pm 2.81^{\mathrm{d}}$ \\
AF & $44.2 \pm 3.4^{\mathrm{b}}$ & $43.12 \pm 0.00^{\mathrm{e}}$ & $71.29 \pm 2.39^{\mathrm{e}}$ \\
\hline
\end{tabular}

${ }^{1}$ Values are expressed as a mean $\pm \mathrm{SD}(n=3) .{ }^{2} \mathrm{EE}$ : ethanol extracts. HF: $n$-hexane fractions. DCMF: dichloromethane fraction. EAF: ethyl acetate fraction. BF: $n$-buthanol fractions. AF: aqueous fraction. ${ }^{3}$ Effective concentration of substance that causes $50 \%$ inhibition. ${ }^{\text {a-e }}$ Means with different superscripts in the same column are significantly different at $p<0.05$.

\subsection{Antioxidant Capacities of R. crispus Extracts and Fractions}

The FRAP assay determines antioxidant activity by measuring electro transport. In this assay, the antioxidant activity was assessed by the reduction of $\mathrm{Fe}^{3+}$-TPTZ to $\mathrm{Fe}^{2+}-\mathrm{TPTZ}$. The FRAP value of the extracts and fractions was the highest in the EAF, followed by the EE, AF, DCMF, BF, and HF (Table 4). The TEAC assay measures scavenging of $\mathrm{ABTS}^{+}$radicals by sulfur oxides through donation of hydrogen atoms or electrons, which are expressed as trolox equivalents. The highest electron-donating capacity was recorded for the EAF $(5.65 \mathrm{mM} \mathrm{TE} / \mathrm{g})$, followed by the DCMF, EE, AF, BF, and HF 
(Table 4). The ORAC assay is an experimental method recommended by the United States Department of Agriculture for the quantification of food antioxidant content based on electron transport capacity. Decomposition of AAPH produces peroxyl radicals, which react with fluorescein, leading to decreased fluorescence. Peroxyl radical scavenging measured as fluorescence reduction is then converted to trolox equivalents (TE). The ORAC value was highest in the EAF (4817 mM TE/g) and decreased in order from DCMF, to EE, then HF, then AF, and finally BF (Table 4).

The antioxidant capacities of $R$. crispus were highest in the EAF and DCMF, which is consistent with their total phenol and flavonoid contents. Similarly, the antioxidant activity of $R$. hastatus extracts has been reported to be highest in the EAF which has high total phenol and flavonoid concentrations [32]. Sahidi and Ambigaipalan [33] have reported that food antioxidant capacity is closely related to the total phenolic and flavonoid contents and have attributed it to the electron or H-atom-donating ability of phenolic hydroxyl groups. In this study, the antioxidant capacities were highest in the EAF and DCMF, which is consistent with their higher concentrations of phenolic and flavonoid compounds.

Table 4. FRAP, TEAC, and ORAC values of Rumex crispus L. root extracts and fractions ${ }^{1}$.

\begin{tabular}{cccc}
\hline Samples $^{2}$ & ${\text { FRAP }\left(\mathbf{m M ~ F e S O}_{4} / \mathbf{g}\right)}$ & TEAC $(\mathbf{m M ~ T E} / \mathbf{g})$ & ORAC $(\mathbf{m M ~ T E} / \mathbf{g})$ \\
\hline EE & $48.14 \pm 0.47^{\mathrm{b}}$ & $2.46 \pm 0.11^{\mathrm{c}}$ & $1396 \pm 204^{\mathrm{b}, \mathrm{c}}$ \\
HF & $13.66 \pm 0.15^{\mathrm{e}}$ & $0.43 \pm 0.06^{\mathrm{f}}$ & $983 \pm 88^{\mathrm{c}, \mathrm{d}}$ \\
DCMF & $37.74 \pm 0.77^{\mathrm{c}, \mathrm{d}}$ & $3.56 \pm 0.11^{\mathrm{b}}$ & $1790 \pm 246^{\mathrm{b}}$ \\
EAF & $135.58 \pm 3.62^{\mathrm{a}}$ & $5.65 \pm 0.00^{\mathrm{a}}$ & $4817 \pm 331^{\mathrm{a}}$ \\
BF & $33.06 \pm 0.80^{\mathrm{d}}$ & $1.97 \pm 0.13^{\mathrm{d}}$ & $909 \pm 121^{\mathrm{d}}$ \\
AF & $40.83 \pm 0.16^{\mathrm{c}}$ & $2.30 \pm 0.13^{\mathrm{c}}$ & $945 \pm 87^{\mathrm{d}}$
\end{tabular}

\footnotetext{
${ }^{1}$ Values are expressed as a mean $\pm \mathrm{SD}(n=3) .{ }^{2} \mathrm{EE}$ : ethanol extracts. HF: $n$-hexane fractions. DCMF: dichloromethane fraction. EAF: ethyl acetate fraction. BF: $n$-buthanol fractions. AF: aqueous fraction. ${ }^{\text {a-e }}$ Means with different superscripts in the same column are significantly different at $p<0.05$.
}

\subsection{Anti-Inflammation Activities of R. crispus Extracts and Fractions}

To assess the anti-inflammatory activities of $R$. crispus extracts and fractions, we measured their cytotoxicities in mouse leukemic monocyte macrophage cells (Raw 264.7). Raw 264.7 cells were treated with $25-400 \mu \mathrm{g} / \mathrm{mL}$ of $R$. crispus extracts and fractions, and cell survival was measured after $24 \mathrm{~h}$ using the WST-1 assay. Cell viabilities of $R$. crispus extracts and fractions are summarized in Figure 1A. The EE, BF, and AF did not show cytotoxicity within the indicated concentration range. The EE and HF were not cytotoxic at a concentration of $25-200 \mu \mathrm{g} / \mathrm{mL}$, but at $400 \mu \mathrm{g} / \mathrm{mL}$ cell survival decreased to $75.24 \%$ and $60.94 \%$, respectively. The EAF showed the highest cytotoxicity, decreasing cell survival to $60.20 \%, 2.62 \%$, and $17.33 \%$ at 100,200 , and $400 \mu \mathrm{g} / \mathrm{mL}$, respectively (Figure $1 \mathrm{~A}$ ).

Excessive NO production from L-arginine due to an overexpression of inducible NO synthase (iNOS) during acute or chronic inflammation is known to accelerate inflammatory responses [34]. We assessed the inhibition of NO production induced by LPS at non-cytotoxic concentrations (25 and $50 \mu \mathrm{g} / \mathrm{mL}$ ) for each of the extract fractions. Consistent with the results of the antioxidant assays the EAF and DCMF showed the highest inhibitions of NO production, while other fractions did not exhibit any inhibitory effects (Figure 1B). Previous studies on the anti-inflammatory activities of R. crispus leaf extracts and fractions have also reported high levels of inflammatory activity in the DCMF and EAF, which agrees with the findings of this study [35]. Based on the results of the NO inhibition assay, we used the EAF for further cell-based experiments.

Cytokines play a pivotal role in inflammatory responses by directly affecting the proliferation and activity of immune cells [36]. Among the pro-inflammatory cytokines, TNF- $\alpha$ is an essential mediator in the development of systemic inflammatory responses, and its synthesis is increased by NO generated by LPS-stimulated macrophages. TNF- $\alpha$ increases the expressions of chemokines and cell adhesion molecules, thereby accelerating pro-inflammatory responses [37]. IL-1 $\beta$ and IL-6 are multifunctional cytokines secreted by macrophages activated by various pro-inflammatory stimuli; these cytokines are also implicated in the induction of autoimmune diseases, and they act by accelerating 
inflammatory responses through autocrine signaling [38]. Figure 2 shows the inhibition of IL-1 $\beta$, IL-6, and TNF- $\alpha$ secretion following EAF treatment using the enzyme-linked immunosorbent assay (ELISA). The secretion of pro-inflammatory cytokines by Raw 264.7 cells was sharply increased following LPS stimulation and decreased after treatment with EAF in a concentration-dependent manner. IL-1 $\beta$, IL-6, and TNF- $\alpha$ were suppressed by $28 \%, 65 \%$, and $68 \%$, respectively, when treated with $50 \mu \mathrm{g} / \mathrm{mL}$ EAF.
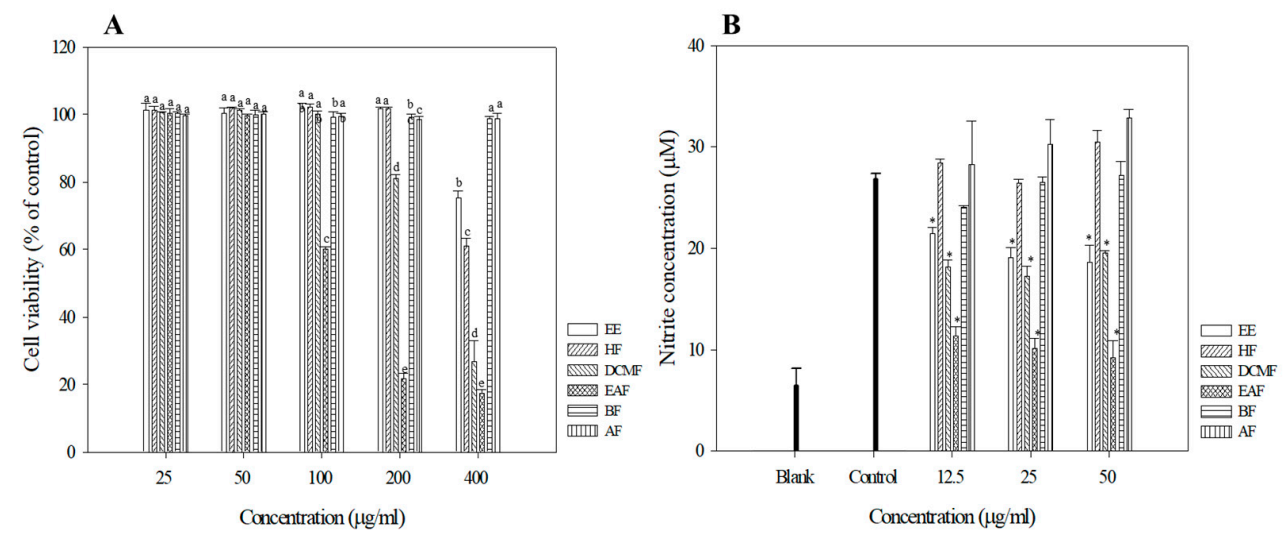

Figure 1. Cell viabilities of $R$ crispus extracts and solvent fractions. (A) NO production (B) in Raw 264.7 cells. RAW 264.7 cells were treated with various concentrations $(25,50,100,200,400 \mu \mathrm{g} / \mathrm{mL})$ of $R$. crispus extracts and fractions for $24 \mathrm{~h}$. Cell viability was measured by MTT assay. RAW 264.7 cells were pre-incubated with 12.5, 25, and $50 \mu \mathrm{g} / \mathrm{mL}$ of extracts and fractions for $1 \mathrm{~h}$ and then treated with $1 \mu \mathrm{g} / \mathrm{mL}$ of LPS for $24 \mathrm{~h}$. The NO production was measured by the Griess reagent system. Data are represented as means \pm SEMs. The different superscripts are significantly different at $p<0.05$. * Statistical significance of the difference between LPS and LPS + sample treatment groups: ${ }^{*} p<0.05$.
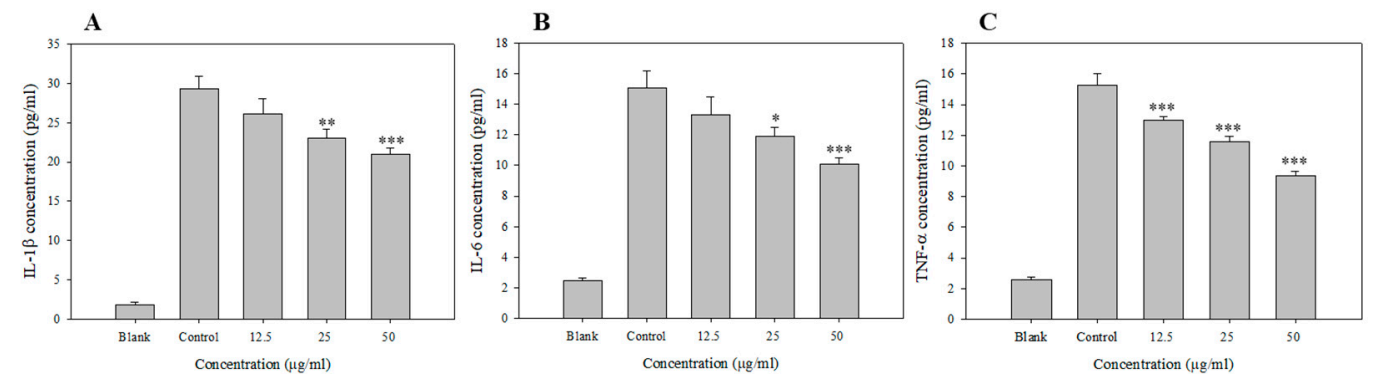

Figure 2. Inhibition of LPS induced IL-1b, IL-6 and TNF-a in the EAF. RAW 264.7 cells were preincubated with 12.5 or $25 \mu \mathrm{g} / \mathrm{mL}$ of EAF for $1 \mathrm{~h}$ and then treated with $1 \mu \mathrm{g} / \mathrm{mL}$ of LPS for $24 \mathrm{~h}$. The IL-1 $\beta$, IL-6, and TNF- $\alpha$ production was measured by ELISA, as described in Materials and Methods. Data are represented as means \pm SEMs. * Statistical significance of the difference between LPS and LPS + sample treatment groups: ${ }^{*} p<0.05,{ }^{* *} p<0.01,{ }^{* * *} p<0.001$.

In a study of the anti-inflammatory activity in R. crispus leaf extracts and fractions, Im et al. [35] found that the EAF displayed higher concentration-dependent activity than the extracts in inhibiting the expression of COX-2 and iNOS involved in the production of $\mathrm{PGE}_{2}$ and NO. In this study, the anti-inflammatory effects were verified by the reduced expression of all the pro-inflammatory cytokines apart from TNF- $\alpha[39]$.

\subsection{Anticancer Activities of R. crispus Extracts and Fractions}

We measured the cytotoxic activities of the fractions against the HepG2 human hepatoma cancer cell line. Among the extracts and fractions, anthraquinone-rich fractions HF and DCMF appeared to be the most potent inhibitors of HepG2 cell proliferation, but the other fractions showed no cytotoxicity. The DCMF inhibited cell growth in a dose-dependent manner. Treatment with HF for $24 \mathrm{~h}$ inhibited 
cell viability with rates of approximately $97 \%, 90 \%, 70 \%, 55 \%$, and $35 \%$ at concentrations of 25,50 , 100, 200, and $400 \mu \mathrm{g} / \mathrm{mL}$, respectively. Treatment with DCMF for $24 \mathrm{~h}$ resulted in inhibition of cell viability with rates of approximately 95\%, 82\%, 61\%, 53\%, and 27\% at concentrations of 25, 50, 100, 200, and $400 \mu \mathrm{g} / \mathrm{mL}$, respectively (Figure $3 \mathrm{~A}$ ).
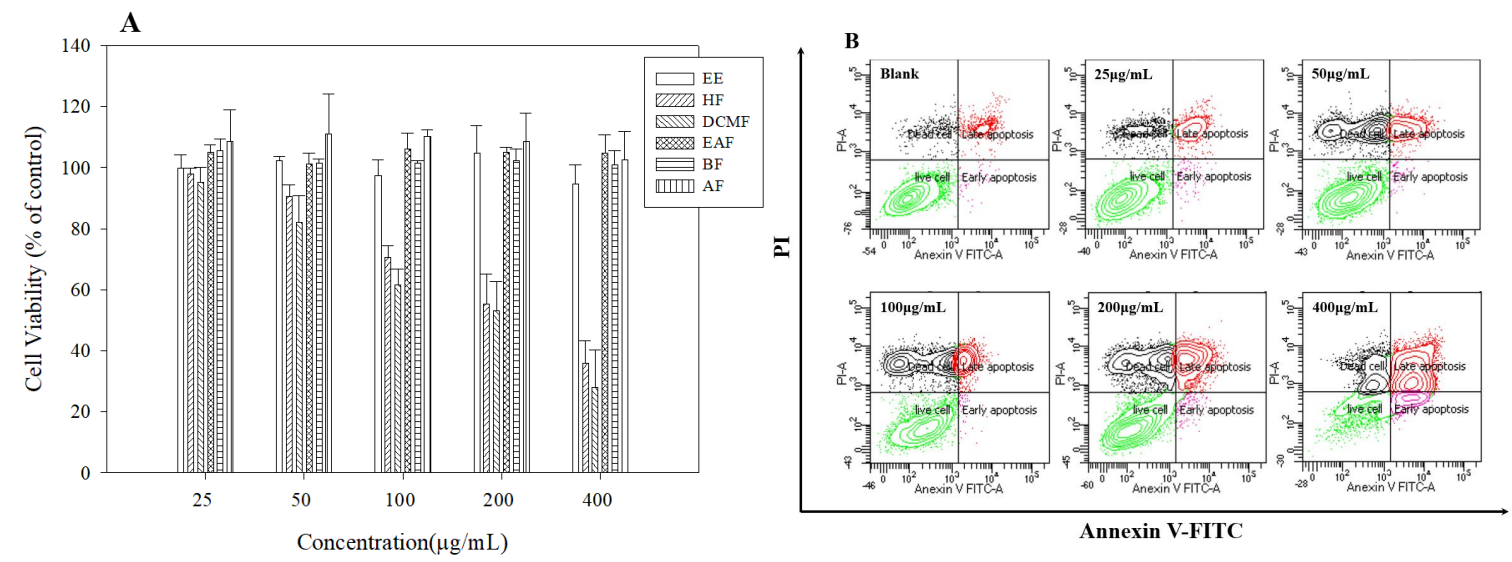

Figure 3. Cell viability of $R$ crispus extracts and solvent fractions. (A) apoptosis induced (B) in HepG2 cells. HepG2 cells were treated with various concentrations $(25,50,100,200,400 \mu \mathrm{g} / \mathrm{mL})$ of $R$. crispus extracts and fractions for $24 \mathrm{~h}$. Cell viability was measured by MTT assay. Flow cytometry analysis of apoptosis after exposure to various concentrations $(25,50,100,200,400 \mu \mathrm{g} / \mathrm{mL})$ of DCMF for $24 \mathrm{~h}$, using annexin V-FITC/PI. The lower right indicates the percentage of early apoptotic cells; the upper right indicates the percentage of necrotic and late apoptotic cells.

A previous study has shown that anticancer activities of Rumex species are closely related to their anthraquinone contents [8,40]. In this study, anticancer activity was highest in the HF and DCMF, which is consistent with their anthraquinone content. Based on these results we used the DCMF for further cell-based experiments. As a decrease in cell proliferation may result from the induction of apoptosis, we investigated whether treatment with the DCMF induced apoptosis in HepG2 cells. HepG2 cells were treated with DCMF at various concentrations; then Annexin V-FITC and PI fluorescence was determined by flow cytometry (Figure 3B). After treatment with 50, 100, 150, and $200 \mu \mathrm{g} / \mathrm{mL}$ DCMF for $48 \mathrm{~h}$, the percentages of apoptotic cells were $13.3 \%, 15.9 \%, 25.6 \%$, and $71.3 \%$, respectively. These results suggest that the DCMF inhibited the proliferation of HepG2 cells by inducing apoptosis in a concentration-dependent manner.

\subsection{Modulation of Apoptotic Regulation}

Bcl-2 proteins play a complex regulatory role in apoptosis [41]. Treatment with DCMF resulted in decreased Bcl-2 expression, while Bax protein expression was increased in a dose dependent manner. DCMF showed increased p53 tumor suppressor protein expression in HepG2 cells (Figure 4A). These results indicate that part of the DCMF-mediated inhibition of HepG2 cells is related to apoptosis through its effects of p53 and Bcl-2 protein expression. In order to determine whether this inhibition is related to the induction of apoptosis, HepG2 cells were exposed to DCMF and their caspase activity was evaluated. DCMF treatment resulted in increased levels of cleaved caspase-3, -8 , and -9 . This result was confirmed by the progressive proteolytic cleavage of the poly (ADP-ribose) polymerase (PARP), a downstream target of activated caspase, in HepG2 cells treated with DCMF (Figure 4B). These data agree with the other experiments that suggest that DCMF treatment induces apoptosis in HepG2 cells.

DCMF-induced apoptosis in HepG2 cell was confirmed by the characteristic pattern of Annexin V/PI staining, activation of caspases (-3, -8, and -9), and cleavage of PARP. Activated caspases regulate the execution-phases of cell apoptosis by degrading specific structural, regulatory, and DNA repair proteins within the cell [42]. Activated caspase-9 then initiates the proteolytic activity of other downstream caspases, such as caspase-3. The activation of caspase-3 results in the cleavage of key 
cellular proteins, such as PARP [43]. Tumor suppressor protein p53 also plays key roles in cell fate, cell growth, and death, via the regulation of the cell cycle proteins [44] and apoptosis induced proteins (Apaf1, Bad, Bax, and Fas) [45]. Treatment with DCMF decreased anti-apoptotic Bcl-2 protein and increased pro-apoptotic Bax protein expression. In addition, DCMF treatment increased p53 tumor suppressor protein levels. These results demonstrate that DCMF-induced apoptosis in HepG2 human hepatoma cancer cells is affected via the induction of p53, activation of Bax, inhibition of Bcl-2, processing of caspases, and cleavage of PARP.

$\mathbf{A}$

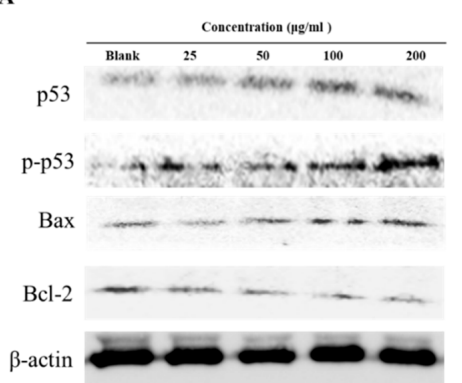

B

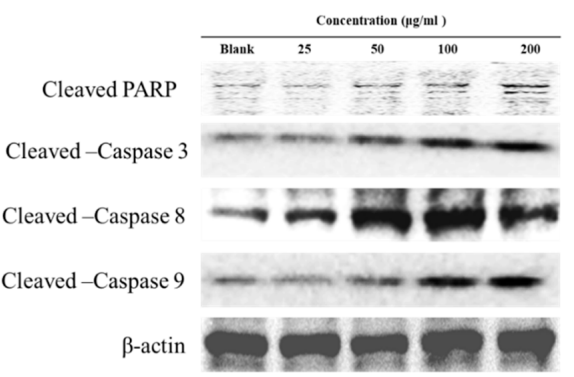

Figure 4. Effects of DCMF on the Bcl-2 family and p53 (A) and caspase family (B) protein expression in HepG2 cells. HepG2 were treated with the indicated concentrations of DCMF for $24 \mathrm{~h}$. The equal amounts of cellular proteins were probed with the indicated antibodies, and the proteins were visualized using an ECL detection system. Actin was used as an internal control.

\section{Conclusions}

Several studies have demonstrated that natural polyphenol-containing products reduce ROS which are risk factors for age-related diseases. This study examined whether R. crispus extracts and fractions could exert any inhibitory effects on oxidative stress-related reactions and inflammation in vitro. The ethanol extracts of $R$. crispus were separated into hexane, dichloromethane, ethyl acetate, butanol, and aqueous fractions based on polarity. Antioxidant activity was evaluated using various assays and was shown to be highest in the DCMF and EAF, corresponding to their high polyphenol and flavonoid contents. In addition, the anti-inflammatory tests revealed that high antioxidant activity correlated with inhibitory effects on NO production, and that the EAF also reduced the secretion of pro-inflammatory cytokines in a concentration-dependent manner. In addition, DCMF was shown to inhibit HepG2 human hepatoma cancer cell growth and induce cellular apoptosis. DCMF-induced apoptosis is facilitated by p53 tumor suppressor protein-mediated Bcl-2 family protein regulation and caspase family protein activation. The results of this study suggest that $R$. crispus could be used as a natural alternative to synthetic antioxidants and anti-inflammatory agents.

Supplementary Materials: The following are available online at http://www.mdpi.com/2076-3921/9/8/726/s1, Figure S1: Chromatogram of Rumex crispus root extract and fractions at $420 \mathrm{~nm}$. a: Aloe-emodin, b: Rhein, c: Emodin, d: Chrysophanol. e: Physcion (EE).

Author Contributions: Conceptualization, T.E. and J.-S.K.; formal analysis, J.-S.K.; investigation, E.K.; methodology, T.E. and E.K.; project administration, J.-S.K. and E.K.; writing-original draft, T.E. All authors have read and agreed to this version of the manuscript.

Funding: This research was supported as a Basic Science Research Program through the National Research Foundation of Korea (NRF) funded by the Ministry of Education (grant number 2013R1A1A2065215).

Conflicts of Interest: The authors have no conflicts of interest to declare.

\section{References}

1. Finkel, T. Signal transduction by reactive oxygen species. J. Cell Biol. 2011, 194, 7-15. [CrossRef] [PubMed]

2. Valko, M.; Leibfritz, D.; Moncol, J.; Cronin, M.T.; Mazur, M.; Telser, J. Free radicals and antioxidants in normal physiological functions and human disease. Int. J. Biochem. Cell Biol. 2007, 39, 44-84. [CrossRef] [PubMed] 
3. Morgan, M.J.; Liu, Z.G. Crosstalk of reactive oxygen species and NF-kappaB signaling. Cell Res. 2011, 21, 103-115. [CrossRef] [PubMed]

4. Mittal, M.; Siddiqui, M.R.; Tran, K.; Reddy, S.P.; Malik, A.B. Reactive oxygen species in inflammation and tissue injury. Antioxid. Redox Signal. 2014, 20, 1126-1167. [CrossRef] [PubMed]

5. Grivennikov, S.I.; Greten, F.R.; Karin, M. Immunity, inflammation, and cancer. Cell 2010, 140, 883-899. [CrossRef] [PubMed]

6. Rahman, I.; Biswas, S.K.; Kirkham, P.A. Regulation of inflammation and redox signaling by dietary polyphenols. Biochem. Pharmacol. 2006, 72, 1439-1452. [CrossRef] [PubMed]

7. Haslam, E. Natural polyphenols (vegetable tannins) as drugs: Possible modes of action. J. Nat. Prod. 1996, 59, 205-215. [CrossRef]

8. Vasaa, A.; Orban-Gyapai, O.; Hohmann, J. The Geneus Rumex: Review of traditional uses, phytochemistry and pharmacoly. J. Ethnopharmacol. 2015, 175, 198-228. [CrossRef]

9. Bello, O.M.; Fasinu, P.S.; Bello, O.E.; Ogbesejana, A.B.; Adetunji, C.O.; Dada, A.O.; Ibitoye, O.S.; Aloko, S.; Oguntoye, O.S. Wild vegetable Rumex acetosa Linn.: Its ethonobotany, pharmacology and phytochemistry-A review. S. Afr. J. Bot. 2019, 125, 149-160. [CrossRef]

10. Yang, J.Y.; Wang, Z.Z.; Mao, X.J.; Xu, Q.L.; Lin, R.C.; Dai, Z. Determination of free and total anthraquinones in 3 kinds of Rumex by HPLC: A comparative study. Chin. J. Pharm. Anal. 2017, 37, 615-623.

11. Jang, S.J.; Kuk, Y.I. Effects of different fractions of Rheum palmatum root extract and anthraquinone compounds on fungicidal, insecticidal, and herbicidal activities. J. Plant. Dis Protect. 2018, 125, 451-460. [CrossRef]

12. Prateeksha; Yusuf, M.A.; Singh, B.N.; Sudheer, S.; Kharwar, R.N.; Siddiqui, S.; Abdel-Azeem, A.M.; Fraceto, L.F.; Dashora, K.; Gupta, V.K. Chrysophanol: A natural anthraquinone with multifaceted biotherapeutic potential. Biomolecules 2019, 9, 68. [CrossRef] [PubMed]

13. Singleton, V.L.; Orthofer, R.; Lamuela-Raventos, R.M. Analysis of total phenols and other oxidation substrates and antioxidants by means of Folin-Ciocalteu reagent. Method Enzymol. 1999, 299, 152-178.

14. Pekal, A.; Pyrzynska, K. Evaluation of aluminium complexation reaction for flavonoid content assay. Food Anal. Method 2014, 7, 1776-1782. [CrossRef]

15. Eom, T.K.; Senevirathne, M.; Kim, S.K. Synthesis of phenolic acid conjugated chitooligosaccharides and evaluation of their antioxidant activity. Environ. Toxicol. Pharm. 2012, 34, 519-527. [CrossRef]

16. Lebel, C.P.; Bondy, S.C. Sensitive and rapid quantitation of oxygen reactive species formation in rat synaptosomes. Neurochem. Int. 1990, 17, 435-440. [CrossRef]

17. Liu, F.; Ooi, V.E.C.; Chang, S.T. Free radical scavenging activities of mushroom polysaccharide extracts. Life Sci. 1997, 60, 763-771. [CrossRef]

18. Zulueta, A.; Esteve, M.J.; Frigola, A. ORAC and TEAC assays comparison to measure the antioxidant capacity of food products. Food Chem. 2009, 114, 310-316. [CrossRef]

19. Benzie, I.F.F.; Strain, J.J. Ferric reducing antioxidant power assay: Direct measure of total antioxidant activity of biological fluids and modified version for simultaneous measurement of total antioxidant power and ascorbic acid concentration. Method Enzymol. 1999, 299, 15-27.

20. Manach, C.; Scalbert, A.; Morand, C.; Remesy, C.; Jimenez, L. Polyphenols: Food sources and bioavailability. Am. J. Clin. Nutr. 2004, 79, 727-747. [CrossRef]

21. Kaur, C.; Kapoor, H.C. Anti-oxidant activity and total phenolic content of some Asian vegetables. Int. J. Food Sci. Tech. 2002, 37, 153-161. [CrossRef]

22. Maisuthisakul, P.; Suttajit, M.; Pongsawatmanit, R. Assessment of phenolic content and free radical-scavenging capacity of some Thai indigenous plants. Food Chem. 2007, 100, 1409-1418. [CrossRef]

23. Malik, E.M.; Muller, C.E. Anthraquinones as pharmacological tools and drugs. Med. Res. Rev. 2016, 36, 705-748. [CrossRef] [PubMed]

24. Lim, J.P.; Park, Y.S.; Hong, M.W.; Kim, D.K. Qunatotative analysis of anthraquinones from the roots of Korean natural Rumex spcies plant. Kor. J. Pharm. 2011, 42, 297-301.

25. Wegiera, M.; Smolarz, H.D.; Wianowska, D.; Dawidowicz, A.L. Anthracene derivatives in some species of Rumex, L. genus. Acta Soc. Bot. Pol. 2007, 76, 103-108.

26. Duval, J.; Pecher, V.; Poujol, M.; Lesellier, E. Research advances for the extraction, analysis and uses of anthraquinones: A review. Ind. Crop. Prod. 2016, 94, 812-833. [CrossRef]

27. Lee, N.J.; Choi, J.H.; Koo, B.S.; Ryu, S.Y.; Han, Y.H.; Lee, S.I.; Lee, D.U. Antimutagenicity and cytotoxicity of the constituents from the aerial parts of Rumex acetosa. Biol. Pharm. Bull. 2005, 28, 2158-2161. [CrossRef] 
28. Yildirim, A.; Mavi, A.; Kara, A.A. Determination of antioxidant and antimicrobial activities of Rumex crispus L. extracts. J. Agric. Food Chem. 2001, 49, 4083-4089. [CrossRef]

29. Elzaawely, A.A.; Xuan, T.D.; Tawata, S. Antioxidant and antibacterial activities of Rumex japonicus HOUTT. Aerial parts. Biol. Pharm. Bull. 2005, 28, 2225-2230. [CrossRef]

30. Ansuya, N.; Gomathi, R.; Manian, S.; Sivaram, V.; Menon, A. Evalution of Basella rubra L., Rumex nepalensis spreng. and Commelina benghalensis L. for antioxidant activity. Int. J. Pharm. Pharm. Sci. 2012, 4, 714-720.

31. RiceEvans, C.A.; Miller, N.J.; Paganga, G. Structure-antioxidant activity relationships of flavonoids and phenolic acids. Free Radic. Biol. Med. 1996, 20, 933-956. [CrossRef]

32. Sahreen, S.; Khan, M.R.; Khan, R.A. Phenolic compounds and antioxidant activities of Rumex hastatus D. Don. leaves. J. Med. Plants Res. 2011, 5, 2755-2765.

33. Shahidi, F.; Ambigaipalan, P. Phenolics and polyphenolics in foods, beverages and spices: Antioxidant activity and health effects-A review. J. Funct. Foods 2015, 18, 820-897. [CrossRef]

34. Aktan, F. iNOS-mediated nitric oxide production and its regulation. Life Sci. 2004, 75, 639-653. [CrossRef] [PubMed]

35. Im, N.K.; Jung, Y.S.; Choi, J.H.; Yu, M.H.; Jeong, G.S. Inhibitoy effect of leaves of Rumex crispus L. on LPS-induced nitric oxide production and the expression of iNOS and COX-2 in macrophage. Nat. Prod. Sci. 2014, 20, 51-57.

36. Ng, S.; Galipeau, J. Concise review: Engineering the fusion of Cytokines for the modulation of immune cellular responses in cancer and autoimmune disorders. Stem Cell Transl. Med. 2015, 4, 66-73. [CrossRef] [PubMed]

37. Bradley, J.R. TNF-mediated inflammatory disease. J. Pathol. 2008, 214, 149-160. [CrossRef]

38. Dinarello, C.A. Immunological and inflammatory functions of the interleukin-1 family. Annu. Rev. Immunol. 2009, 27, 519-550. [CrossRef]

39. Ishihara, K.; Hirano, T. IL-6 in autoimmune disease and chronic inflammatory proliferative disease. Cytokine Growth F R 2002, 13, 357-368. [CrossRef]

40. Xie, Q.C.; Yang, Y.P. Anti-proliferative of physcion 8-O-beta-glucopyranoside isolated from Rumex japonicus Houtt. on A549 cell lines via inducing apoptosis and cell cycle arrest. BMC Complement. Altern. Med. 2014, 14, 377. [CrossRef]

41. Borner, C. The Bcl-2 protein family: Sensors and checkpoints for life-or-death decisions. Mol. Immunol. 2003, 39, 615-647. [CrossRef]

42. Casciolarosen, L.A.; Miller, D.K.; Anhalt, G.J.; Rosen, A. Specific cleavage of the 70-Kda protein-component of the U1 small nuclear ribonucleoprotein is a characteristic biochemical feature of apoptotic cell-death. J. Biol. Chem. 1994, 269, 30757-30760.

43. Li, P.; Nijhawan, D.; Budihardjo, I.; Srinivasula, S.M.; Ahmad, M.; Alnemri, E.S.; Wang, X.D. Cytochrome c and dATP-dependent formation of Apaf-1/caspase-9 complex initiates an apoptotic protease cascade. Cell 1997, 91, 479-489. [CrossRef]

44. Issaeva, N. p53 signaling in cancers. Cancers 2019, 11, 332. [CrossRef] [PubMed]

45. Chipuk, J.E.; Green, D.R. Dissecting p53-dependent apoptosis. Cell Death Differ. 2006, 13, 994-1002. [CrossRef] [PubMed]

(C) 2020 by the authors. Licensee MDPI, Basel, Switzerland. This article is an open access article distributed under the terms and conditions of the Creative Commons Attribution (CC BY) license (http://creativecommons.org/licenses/by/4.0/). 